\title{
America's Next Top Model: Análisis del potencial carácter formativo de un reality show de belleza
}

\author{
Recibido: 19 de noviembre de 2014 \\ Aceptado: 11 de junio de 2015 \\ Publicado: 30 de octubre de 2015
}

\author{
Tomás Atarama Rojas \\ tomas.atarama@udep.pe
}

Alexandra Coloma Núñez

alexacoloma@gmail.com

Universidad de Piura (Perú)

Resumen: La belleza ha cobrado una mayor relevancia en la sociedad gracias al protagonismo que los medios de comunicación le han dado. La tendencia de los últimos años es crear programas de telerrealidad que estén relacionados con la belleza del hombre; en este marco, la presente investigación analiza los comentarios de los jueces de la temporada 19 del reality show America's Next Top Model con la finalidad de descubrir si este formato relacionado con la belleza puede llegar a transmitir un mensaje formativo en una época en la que los reality shows son catalogados como televisión de baja calidad. A partir del análisis de los comentarios de los jueces se llega a la conclusión que en el programa se transmite una visión de la belleza que no se reduce al mero aspecto físico, sino que atiende también a la personalidad y actitud de las personas.

Palabras clave: Reality show, belleza, televisión, America’s Next Top Model.

\begin{abstract}
The presence of beauty in society has now a leading role thanks to the relevance that social media has given it. There is a tendency to elaborate reality TV shows based on beauty. This article analyses the comments of the judges of America's Next Top Model Season 19th to discover if the message in this show can be transmitted as a positive message in a time where reality shows are cataloged as low quality television. After a hard analysis of the season, we can say that the value of the beauty for the jury is the one learn during the contest.
\end{abstract}

Key words: Reality show, Beauty, Television, America's Next Top Model. 


\section{Introducción}

America's Next Top Model es un reality show que fue estrenado en mayo de 2003. Este programa ha sido creado, producido y presentado por la modelo de Victoria's Secret, Tyra Banks. El show consiste en elegir entre 14 y 15 participantes que convivirán mientras permanezcan en el programa, tendrán retos semanales y sesiones de fotos. Al final de cada semana, una de las participantes será eliminada. La serie original, hasta el año 2014, ha alcanzado las 21 temporadas. El formato de Banks ha sido adaptado y vendido a más de 50 países.

A pesar del éxito comercial, muchas veces los reality shows son catalogados como "telebasura" porque se considera que "no son más que un conjunto de programas de televisión cuyos contenidos son muy pobres tanto en la propuesta cognitiva como en la socio-afectiva que nos brindan" (Arboccó y O’Brien, 2012: 44). El reality show es un formato que llama y atrae a las audiencias; el interés por la realidad y el atractivo del espectáculo son dos de los factores de la televisión que más llaman la atención (Cotelo, 1994).

Los reality shows son muy exitosos dentro de la programación televisiva, divierten a los telespectadores y logran altas audiencias. Al examinar America's Next Top Model nos enfrentamos a un reality famoso y seguido por muchos; pero, también, renegado por otros. La pluralidad de opiniones acerca de un reality relacionado con la belleza humana nos invitan a hacer un estudio riguroso al respecto para determinar con fundamento si existen rasgos que resulten acordes con las exigencias que se plantean a una televisión de calidad, como que muestren una visión integral y humana de los temas que tocan, y eviten la mera superficialidad y el morbo.

En este sentido, con el análisis del reality show America's Next Top Model, la investigación pretende averiguar, a través del estudio de los comentarios de los jueces, si la temporada 19 del programa puede ser considerada como una propuesta de bajo nivel para el espectador o, si por el contrario, se trata de un contenido con un potencial carácter formativo para el público. Así, el análisis de los comentarios de los jueces servirá para valorar a qué cuestiones dan relevancia al juzgar la belleza de las participantes. De este modo, podemos averiguar si lo que dicen transmite una concepción integral de la belleza o si se limita a reflejar una visión superficial de la misma.

\section{Marco teórico}

\subsection{El reality show como espectáculo de la realidad}

La televisión es un instrumento que tiene la capacidad de sociabilización y formación de conciencias, sus programas transmiten ideologías y valores que pueden ser provechosos o no para quienes conforman la sociedad (León, 2009). La televisión ha permanecido unida 
a la realidad desde su aparición ${ }^{1}$, este medio de comunicación siempre ha sido una ventana en la que se ha podido observar un sinnúmero de sucesos contemporáneos (Perales, 2011). Al unirse la televisión y la realidad se abrió un nuevo mundo interesante para el hombre, que hasta ahora está dentro de su menú televisivo. La "televisión-realidad" se ha convertido en un fenómeno que se estudia igual que el drama y la noticia, esto es inusual por el corto tiempo que el género tiene con respecto a otros (ibídem).

En los años ochenta, Umberto Eco introduce el término "neotelevisión", con el cuál nace un hipergénero televisivo llamado "docudrama", en el que se explota la autenticidad de situaciones y de protagonistas reales (Costa, 2010). Los docudramas invadieron los canales de la mayoría de países a partir de los años noventa. En este tipo de programas se muestra a personas reales viviendo el día a día y exponiendo parte de su vida privada ante las cámaras. Es difícil tener un concepto exacto de este género porque se encuentra en un constante proceso de hibridación ${ }^{2}$, el cual combina elementos de ficción e información (León, 2009).

Con la neotelevisión y la aparición del docudrama surgen los reality shows como un género que muestra al público los aspectos más dramáticos de la realidad cotidiana. El reality show es un género televisivo "muy importante en la historia de las formas de espectacularización entre televisión y audiencias, ya sea a través de la información, de la ficción o del entretenimiento" (Castro, 2002: 46). Los reality shows se caracterizan por tener la fidelidad de un público que se siente atraído por temas de amor, de belleza, de violencia o de amistad; pero no son solo los temas lo que atrapan al espectador sino el observar a alguien como él en la pantalla. La producción se encarga de la selección de los momentos más significativos, por lo tanto, es cuestionable el término realidad que se utiliza en este formato ( $c f$. Perales, 2011).

“A partir de la conjunción de elementos de contenido, fórmulas expresivas y dinámicas de producción de programas tanto informativos como ficcionales empieza a hablarse del docudrama como género" (León, 2009: 25). Dentro del docudrama está el reality show, el cual tiene una gran variedad de tipos: el docushow (hacen de la vida privada un espectáculo), el coaching show (los participantes poseen un problema que debe solucionarse a partir del asesoramiento de especialistas), el casting show (con jueces populares para la realización del casting), el docuquiz (se hacen preguntan íntimas para conseguir un premio) y el docugame (programa concurso que puede ser de convivencia, supervivencia o de superación).

Este tipo de programas tienen su primer antecedente en el programa de cámara oculta Candid Camera en 1948. Pero se puede decir, en un sentido moderno, que el fenómeno del reality show saltó a la fama con la serie documental An American Family (1973), en

1. El discurso televisivo de la telerrealidad cumple una función socializadora desde el plano emotivo que convierte a la realidad en un espectáculo (Mateos-Pérez, 2011).

2. La hibridación de la que se habla, de idas y formatos, es necesaria para sorprender al espectador audiovisual, el que a veces puede pensar que todo está inventado (García, 2011). 
la que se cuenta la vida de una familia tradicional y convencional estadounidense, la cual toma un giro con el divorcio de los padres. Ese tipo de situaciones inesperadas son las que inmiscuyen al televidente invitándolo a ser partícipe de una vida ajena. En su momento, el programa de telerrealidad Big Brother (1999) tuvo una gran repercusión en Holanda, se consideraba como uno de los programas de concurso más exitoso al contar con una gran audiencia. Este formato rápidamente se vendió a varios países. También Survivor (2000) rompió récords ${ }^{3}$ y obtuvo un beneficio de veintiocho millones de dólares (Perales, 2011).

Lo exitoso de los reality shows que nombramos es que mezclan el encierro, el concurso y la interactividad. Los personajes tienen poca o ninguna comunicación con sus conocidos y deben acostumbrarse a convivir con extraños, el concurso apoya a la trama y le da un hilo al programa; y la interactividad permite que el televidente se convierta en "teleparticipante"; y esto satisface a los consumidores (Maestre, 2005). Muchas personas se hicieron famosas solo con el hecho de estar presentes en un reality show. En la actualidad, el éxito de los personajes del reality show está en el desarrollo de sus talentos y de sus habilidades (Ganetz, 2011).

Los programas de telerrealidad han ido evolucionando y se han vuelto más individualizados, para así llegar a audiencias más específicas, con un predominio del público femenino como principal target de estos programas (Perales, 2011). Sin embargo, pese a su crecimiento y diversificación, los reality shows son considerados por muchos como televisión basura ${ }^{4}$ (Barrera, 1994). Los que critican estos programas se basan en que "no cumplen el fin altruista y caen más bien en la explotación del dolor ajeno, que es exhibido a una audiencia" (Martínez, 2007: 90). Además, señalan que se regodean con el sufrimiento y "con la muestra más sórdida de la condición humana" (Arboccó y O’Brien, 2012: 44). Pero justamente para analizar el alcance de estas afirmaciones, consideramos oportuno realizar un estudio que considere el contenido del programa a partir de las valoraciones que hacen los jueces.

Los reality shows han causado controversia: se han considerado como programas sensacionalistas que utilizan tácticas de mal gusto con la finalidad de atraer y mantener al espectador. Los críticos temen que por crear un efecto máximo de drama, los productores distorsionen la realidad mezclando hechos y ficción; y así el televidente no podrá distinguir que lo que se le presenta en la televisión sea falso o real (León, 2009).

Como se aprecia, el formato que se pretende analizar tiene diversas aristas que son susceptibles de ser investigadas; pero en esta investigación pretendemos únicamente aproximarnos al aporte cognoscitivo que puede ofrecer un reality show. En el caso concreto de análisis este aporte se medirá en función de las valoraciones que hacen los jueces del programa sobre la belleza de las participantes y su actitud como posibles modelos

3. El capítulo final de esa temporada lo sintonizaron 51 millones de personas (Aizen, 2000).

4. En el Informe del Centro de Investigaciones Sociológicas del 2004, sobre el consumo de televisión en España, más del cincuenta por ciento de los españoles opinó que la televisión relacionada con los reality shows en España es vulgar y de mal gusto (Martínez, 2007). 
profesionales. Con la finalidad de poder estudiar adecuadamente la visión de belleza que transmiten los jueces, en el siguiente apartado ahondaremos en el concepto de belleza y el modo en que se le representa en los medios de comunicación.

\subsection{Una visión de la belleza humana y su representación en los medios de comunicación}

La belleza es un concepto muy amplio que muchas veces es difícil de definir, es uno de los enigmas del pensamiento universal que no han sido resueltos de modo categórico aún (Murolo, 2009). Se puede encontrar a la belleza en cualquier aspecto relacionado con la vida, ya sea música, arte, literatura; todo se puede catalogar como bello o no. La belleza busca darle sentido a la vida del hombre para que así él pueda encontrar el sentido del mundo ${ }^{5}$, la belleza está en todas las actividades humanas (Mansur, 2012). La belleza está influenciada por factores culturales, históricos y personales que no se determinan con precisión (Gardner, 2011).

Para saber qué es la belleza se necesita de un conocimiento y de un deseo humano; esto se relaciona con la armonía pues es el único modo de nombrar la belleza con validez universal (Bosch, 2012). Desde hace mucho tiempo, la belleza ha sido una pieza fundamental para la humanidad; las mujeres utilizaban métodos para el cuidado de la piel, la silueta y los cabellos para verse bellas. En la actualidad, vivimos en una época en la que la sociedad bombardea a niños y a adultos con mensajes relacionados con la importancia de ser bello, "la publicidad estimula la imaginación de manera reduccionista con todo lo que tiene que ver con su belleza física" (Arriaga, 2008: 51).

La belleza trabaja en conjunto con las facultades humanas, cuando nos enfrentamos ante algo bello no solo lo captamos con la inteligencia y los sentidos, sino que nuestra sensibilidad y voluntad también intervienen; el encuentro con lo bello hace que las personas se involucren integralmente a la hora de captarla (Athié, 2012). Es por eso, que la forma de la belleza solo es exclusiva de los seres humanos "no hay una experiencia estética animal porque no hay una función biológica unida directamente a ella” (Bosch, 2012: 55).

Cuando se tiene el primer impacto con lo bello se debe tener un momento para reflexionar acerca de ello, se necesita de la contemplación para preguntar el por qué realmente algo llega a agradar (Cabrera, 2012). Es un hecho que lo que le puede parecer bello a una persona le pueda parecer lo contrario a otra. Lo que existe en el mundo son ciertos patrones que catalogan y de cierta manera delimitan lo que es bello. Sin embargo, se puede afirmar que el exceso de lo externo y su desvinculación con lo interior de la persona vulneran la verdadera belleza, pues lo propio de la belleza es unir estos dos aspectos, darle armonía (Bosch, 2012).

5. La belleza es "fuente creativa de exaltación y de adoración para todo lo que de alguna manera enaltece la sensibilidad y la conciencia del ser humano, porque los seres humanos no solo tenemos una sensibilidad, sino que tenemos una conciencia" (Rosario-Calender, 2012: 582). 
Al caracterizar algo como bello se debe tener en cuenta que inconscientemente se ha pasado por un juicio estético. Hay tres momentos antes de alcanzar propiamente el juicio estético:

- El primer momento es el estímulo sensorial cuando uno se enfrenta con lo bello. Este es el aspecto primario de la belleza, que es el estímulo externo que proviene de la realidad y que afecta a nuestros sentidos.

- El segundo momento es la reacción afectiva que se produce en nosotros frente a la realidad que percibimos, aquí se puede afirmar que "vemos" con los sentimientos; la voluntad puede apetecer o no lo que se le presenta desde fuera como algo estético o no, y esto ya no depende únicamente del aspecto físico o externo de algo, sino de su sentido.

- El tercer momento implica ya a la persona en su valoración respecto a lo que le aparece como bello, en este momento la belleza invoca su carácter reunitivo, de armonía, y se exige que aquello que sea bello apele a un sentido virtuoso de la persona. En este escenario es que se puede afirmar que hay belleza en actos de altruismo o en el sacrificio de una madre.

Y finalmente se presenta el juicio estético que es el resultado de los pasos anteriores. Pero esos pasos no son independientes uno de otros, el juicio estético es uno solo y es el conjunto de estos elementos lo que constituye la belleza. Esta debe ser la manera como se debe adjetivar algo como bello (Soley-Beltran, 2012).

En la actualidad, son los medios de comunicación los que reflejan la realidad y también quiénes aproximan una manera de entender a las personas y su belleza. Son estos los que aportan al proceso de socialización y hacen patentes los códigos culturales con los que se interpreta el entorno (Loscertales y Núñez, 2009). Los medios de comunicación pueden influir en la construcción de una visión estereotipada de la realidad. A efectos del tema de investigación, podemos afirmar que la imagen de la mujer en los medios de comunicación obedece a unos estereotipos en los que se le reduce, mayormente, a su mera corporeidad. $\mathrm{Y}$ esto es lo que muchas veces se critica a los medios. Sin embargo, los medios también pueden ser los promotores de la diversidad y multiculturalismo.

En la actualidad, por la influencia y protagonismo que tienen los medios de comunicación en la sociedad y su alto componente visual, la noción de la belleza se ha reducido a lo exterior y es confundida con la superficialidad o la banalidad. Esta deformación de la belleza ha sido atribuida en algunos casos a la televisión y la publicidad. Estas formas de comunicación han desvinculado la apariencia física del mundo interior de la persona, aspectos que deben permanecer unidos para que se pueda hablar de una verdadera belleza (Bosch, 2012).

Luego de haber estudiado la noción de belleza y el modo en que se percibe y se juzga en los medios de comunicación, pasamos a relacionar estos conceptos con America's Next Top Model, el reality show a analizar. En el siguiente apartado se explicará el reality show y su relación con la belleza humana, así se darán a conocer las características propias del programa en la temporada 19. Del mismo modo, se pasa a detallar la metodología de investigación. 


\section{Material y métodos}

\subsection{Material: America's Next Top Model}

America's Next Top Model es un programa de televisión que pertenece al formato de los reality show de belleza. La convivencia, los retos y las eliminaciones semanales hacen de este programa el pionero en este tipo de concursos de belleza. La popularidad de America's Next Top Model ha hecho que cada temporada tenga características particulares, donde se busca a diferentes tipos de modelo (Loverude, 2011). Las aspirantes a modelos envían un video o asisten al casting presencial; después de una selección, la producción del programa las invita a la etapa de audiciones en la que cada una tiene una entrevista con los jueces.

Este reality show presenta un mundo que muchas veces se torna ideal en el que las mujeres jóvenes tienen la oportunidad de trabajar con profesionales que las peinen y las maquillen, además usan ropa de diseñador que utilizarán para cada sesión de fotos y son fotografiadas por fotógrafos famosos. Asimismo, viven en una mansión lujosa y opulenta (ibídem).

Como la mayoría de reality shows, America's Next Top Model tiene su base en el realismo y en el espectáculo. Uno de los principales cambios que se dio en ANTM fue en la temporada 19 en la que se incluyó la participación activa del público mediante la votación. Para la temporada 19, en el año 2012, cambia la dinámica del show: es la primera vez que se incluye la opinión de los fans del show. Además, cada juez califica las fotografías del 1 al 10; la suma de cada juez más la votación del público da un puntaje a cada concursante. Los jueces de esta temporada, aparte de Tyra Banks, son Kelly Cutrone que es una empresaria dedicada a la moda, Rob Evans un modelo británico y Johnny Wujek, el encargado de la dirección creativa de las sesiones de fotos; también hay un personaje nuevo que es Bryan Boy, un blogger que se encarga de transmitir las opinión del público. Esta temporada de ANTM se llamó "College-edition" porque se eligieron a chicas que asisten a la universidad.

Este reality show, además de ser un concurso de belleza, es un reality tipo escuela en el que al participante se le capacita. La participante recibe consejos que buscan desarrollar su actitud y profesionalismo como modelo. Esto hace que haya una transformación de comportamiento que los ayudará en el ámbito profesional de su vida (Oliva, 2009). Las participantes reciben lecciones sobre modelaje, pasarelas, entrevistas, aplicación de maquillaje, estilo personal, y presentación. Un tópico común en America's Next Top Model es la idea de transformación. Las participantes no solo se transforman físicamente, también tienen que desarrollar una personalidad "top model". Muchas mujeres de ciclos anteriores afirmaron en sus entrevistas de salida que toda su vida cambió desde su experiencia en ANTM (Loverude, 2011).

En el reality show que analizaremos se muestra la belleza desde diferentes puntos de vista, no sólo se habla del físico del participante, sino que se apela a diferentes categorías de valoración como la personalidad, la forma de ser de la concursante, la forma cómo se desenvuelve ante cámara y ante el público en general; y sobre todo si tiene las características que los jueces buscan en una modelo relacionada a fotografías y a pasarelas. 
Como material de análisis se ha seleccionado la temporada 19 de America's Next Top Model. Se ha optado por este material en función de los siguientes criterios:

- Se trata de un reality show de belleza, donde los jueces son destacados personajes del ámbito de la moda.

- Las valoraciones de los jueces siguen un patrón que permite un porcentaje de participación similar durante toda la temporada.

- Se trata de la última versión del programa en la que participan solo mujeres.

\subsection{Metodología de investigación}

En cuanto a la metodología para examinar el reality show America's Next Top Model, se empleó como técnica de investigación el análisis de contenido, caracterizado por estudiar las ideas expresadas en un material comunicativo para luego cuantificarlas. Además, esta técnica permite y acredita al investigador a abstraer e interpretar la muestra más allá de su contenido explícito. En esta investigación se realiza el análisis de contenido de los comentarios que los jueces realizan respecto a cada una de las participantes. No es el objetivo de este estudio valorar el tratamiento estético o la estructura narrativa del programa, sino aproximarse a la concepción de belleza que se transmite en este reality show a través de los comentarios que los jueces realizan, ya que este es el aspecto que evidencia mejor la concepción que se transmite de la belleza en el programa.

Para diseñar la ficha de análisis de contenido, se elaboró primero una matriz que esbozaba los diferentes aspectos que los investigadores consideraban que se podían valorar en el concurso de belleza, según una primera aproximación empírica al programa. La matriz se testeó en el $50 \%$ de las unidades de análisis (6 programas), y se encontró que de las siete categorías de análisis esbozadas en la matriz, únicamente seis se correspondían con los comentarios de los jueves ${ }^{6}$. Así, el diseño final de la ficha de análisis de contenido contempló solo las seis categorías que englobaban los diferentes comentarios de los jueves. Se realizó nuevamente el testeo de la ficha de análisis de contenido y se comprobó un nivel alto de confiabilidad, porque todos los comentarios podían ser valorados según las categorías diseñadas.

Las seis categorías que se utilizaron en el análisis de contenido se exponen a continuación:

- Dominio escénico: el dominio escénico es un argumento que utilizan los jueces para valorar la conexión que logra la participante con el entorno en el que trabaja, ya sea en fotografías, en pasarelas o en encuentros con el cliente.

\footnotetext{
6. La categoría que se descartó fue la ruptura con los estándares contemporáneos de belleza. Los investigadores consideramos inicialmente que los jueces podrían utilizar expresiones que reconocieran que la participante tenía una belleza distinta a la que hay hoy en las pasarelas, una belleza peculiar (poco común en el mundo del modelaje); pero finalmente no se encontró este tipo de comentarios.
} 
- Expresión facial: la expresión facial es la categoría que evalúa el cómo la participante puede llegar a transmitir sentimientos y emociones tan solo con la mirada y los gestos del rostro. Para los jueces esta categoría dice mucho de la profesionalización de la participante como modelo y de lo aprendido durante todo el programa.

- Contextura física: la contextura física es el argumento que apela a la belleza externa y corporal de la participante. En esta categoría se hace alusión a la apariencia física, a lo netamente corpóreo, lo que se ve a simple vista, lo exterior de la persona.

- Lenguaje corporal: se diseñó la categoría del lenguaje corporal para agrupar los comentarios de los jueces sobre cómo la participante maneja sus ángulos y las posturas que le son convenientes para cada situación del modelaje.

- Actitud ante los jueces: en esta categoría se considera la forma cómo las participantes reciben y responden los comentarios positivos o negativos que se hagan de ellas. Es esencial que cada participante sea auténtica en su manera de ser para personificar a la súper modelo que se quiere.

- Personalidad: esta categoría apela a la forma de ser y de pensar de cada una de las participantes. Para los jueces es muy importante el cómo es la participante frente a sus compañeras y frente a sus superiores; y si tiene la capacidad de ser la representante del programa.

En base a las seis categorías enunciadas, se valoró los comentarios de los cuatro jueces del concurso: Tyra Banks, Kelly Cutrone, Rob Evans y Johnny Wujek. Luego del análisis se pudo cuantificar las referencias que se hacía a cada una de las categorías, a partir de esto y del marco teórico presentado se puede inferir algunas cuestiones respecto a la concepción de belleza que se transmite en el programa. A continuación, se expondrán los resultados de este análisis, lo que nos permitirá obtener una serie de conclusiones y, por ende, se validará o rechazará la hipótesis de este estudio.

\section{Presentación de los resultados}

En función de los argumentos más recurrentes, se podrá inferir posteriormente a qué aspectos se da relevancia para determinar si una de las participantes puede ser una modelo profesional. Si bien los jueces no necesariamente se refieren a la belleza de modo explícito, se toma como premisa que una modelo es valorada por su belleza (entendida en sentido amplio), que se muestra en diferentes aspectos que se han ido profesionalizando en el mundo del modelaje. A continuación, se presentan los resultados del análisis de contenido de los 12 programas de la temporada 19 de America's Next Top Model. Se contabilizó y clasificó un total de 411 comentarios de los jueces. 
Figura 1: Recurrencia de categorías en America's Next Top Model.

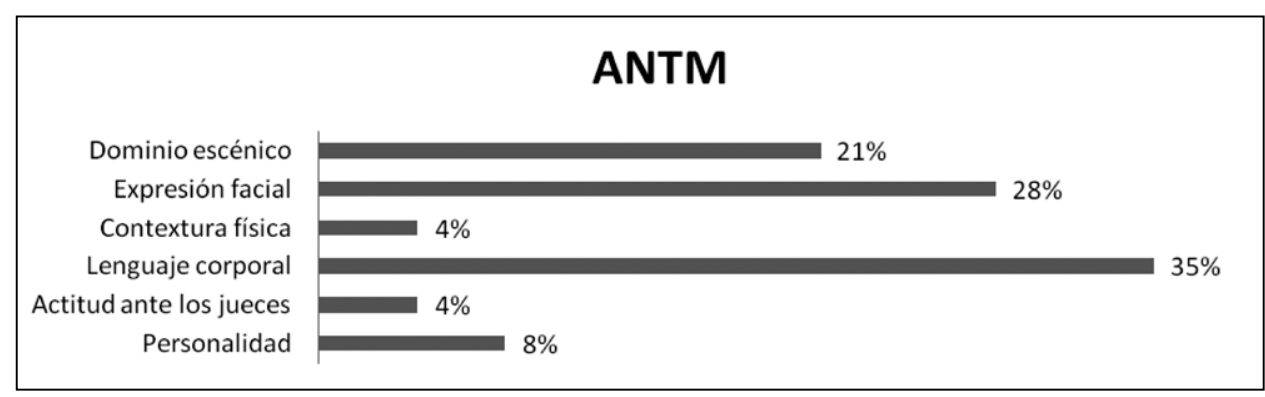

Fuente: Elaboración propia.

En el reality show ANTM, los jueces le dan mayor relevancia al lenguaje corporal (35\%) de las participantes, teniendo en cuenta los ángulos de su cuerpo y lo que transmiten las poses que realizan. En segundo lugar de importancia está la expresión facial de la participante (28\%), lo que transmite su rostro y su mirada. Por el contrario, las categorías a las que menos se apela son la actitud de las participantes frente ellos $(4 \%)$ y a la contextura física de las participantes (4\%). Como se ve, hay una marcada distancia entre los tres argumentos más empleados para valorar el desempeño de las concursantes y los tres argumentos menos utilizados. Posteriormente, se valorará esta marcada diferencia; por ahora, a continuación, se presentan los resultados detallados según cada juez.

Figura 2: Recurrencia de categorías en Tyra Banks.

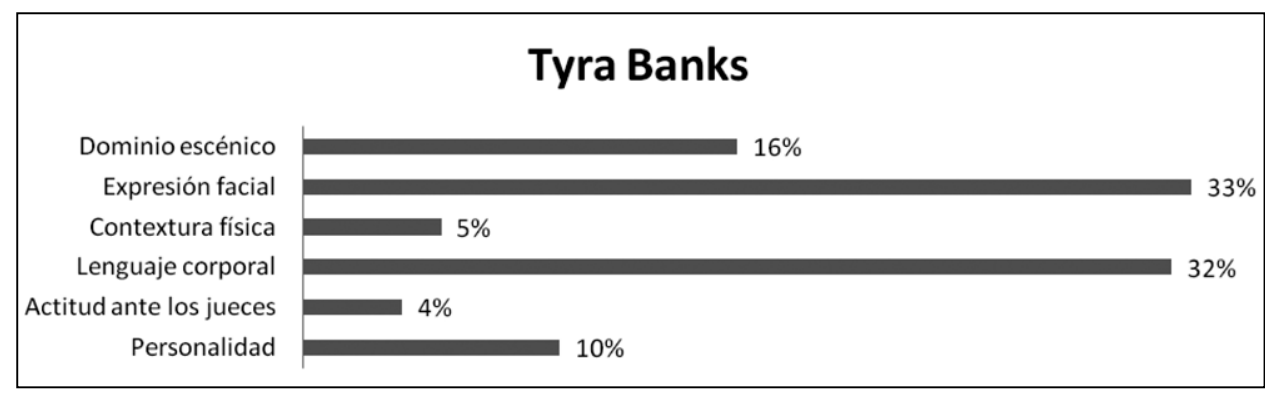

Fuente: Elaboración propia.

Para Tyra Banks, la expresión facial (33\%) y el lenguaje corporal (32\%) son lo más importante en una modelo. Con $16 \%$ destaca también el dominio escénico como un rasgo relevante que representa la profesionalización del modelaje. Durante toda la temporada, Banks pone énfasis en la expresión facial utilizando un término que ella acuñó, smize, que significa "sonreír con los ojos". Es en el último capítulo en el que ella hace mayor referencia a este argumento para juzgar a las 3 últimas participantes teniendo en cuenta su avance durante el concurso. 
Figura 3: Recurrencia de categorías en Kelly Cutrone.

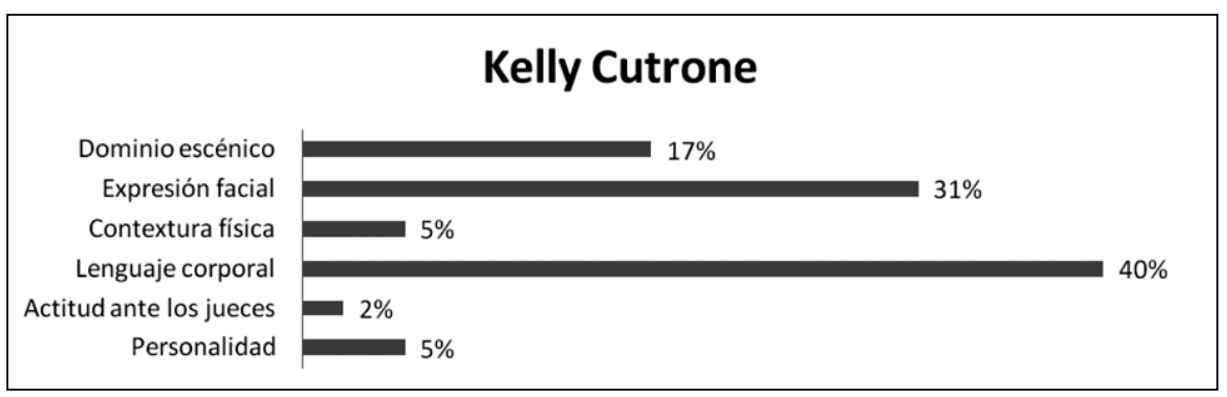

Fuente: Elaboración propia.

Durante la temporada 19 de ANTM, Kelly Cutrone hace referencia al lenguaje corporal en un $40 \%$, siendo el argumento más importante de la jueza. En los capítulos 4 y 5 da especial relevancia a la postura del cuerpo para lograr una buena foto. En un segundo lugar está la expresión facial con 31\%. La contextura física y la personalidad no son muy relevantes, cada una ocupa un 5\%, y la actitud ante los jueces $(2 \%)$ ha sido el aspecto menos considerado.

Figura 4: Recurrencia de categorías en Rob Evans.

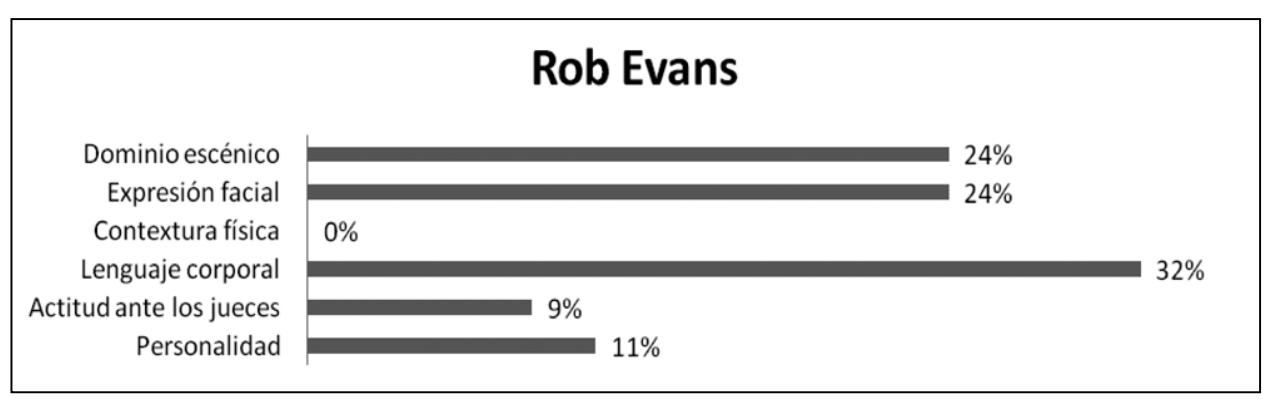

Fuente: Elaboración propia.

Para Rob Evans, el primer lugar lo ocupa el lenguaje corporal (32\%), en segundo lugar se encuentran la expresión facial (24\%) y el dominio escénico (24\%). Evans en el último capítulo de la temporada hace hincapié en el movimiento de los brazos y de las piernas, como un argumento fundamental para elegir a la ganadora. Por otro lado, es interesante precisar que Rob Evans es el juez que más considera a la personalidad dentro de sus argumentos (11\%). 
Figura 5: Recurrencia de categorías en Johnny Wujek.

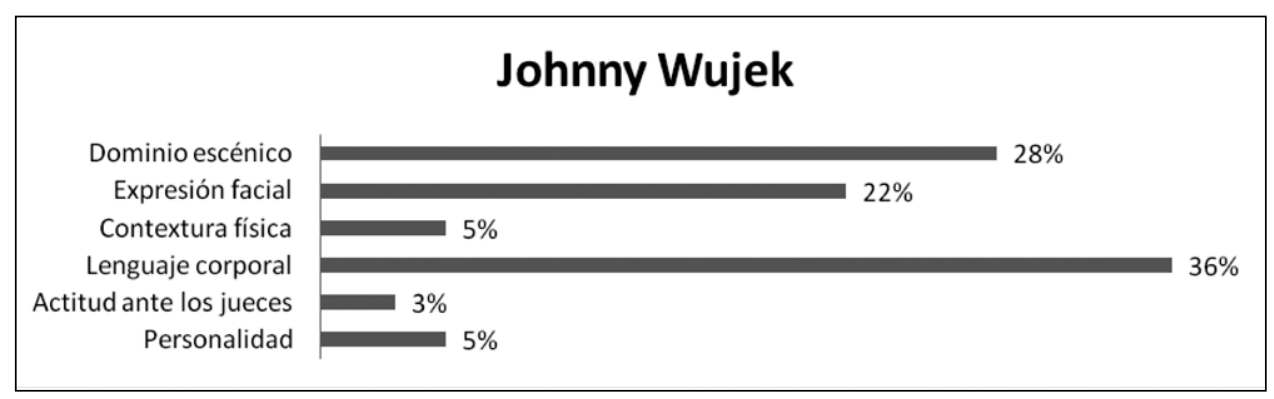

Fuente: Elaboración propia.

Para el director creativo Jhonny Wujek, el lenguaje corporal (36\%) es indispensable para valorar a una modelo. En el cuarto capítulo menciona durante la sesión de fotos reiteradas veces que las participantes necesitan diversidad y para eso necesitan mover su cuerpo. Asimismo, el dominio escénico (28\%) y la expresión facial (22\%) de las participantes son importantes en cuanto muestran su aprendizaje y evolución en la competencia.

\section{Análisis de los resultados}

Como se ha visto en apartados anteriores, el reality show como género puede estar relacionado con contenidos vulgares y de mal gusto por mostrar rasgos cotidianos de la realidad, y por explotar el morbo a partir de aspectos privados e íntimos de los participantes; sin embargo, luego de realizar la investigación encontramos que en America's Next Top Model las valoraciones de los jueces obedecen, más bien, a un intento de profesionalizar las actividades que competen al modelaje. No hay referencias a la privacidad o intimidad de las participantes, todos los comentarios obedecen a la finalidad de la competencia.

Con el análisis del reality se reafirma el hecho de que para ganar el concurso se necesita de técnicas que se irán adquiriendo y aprendiendo durante el programa. "Se admite que la belleza no es innata, no es un don sino que se adquiere, da trabajo" (Walzer, 2009: 207). Son el lenguaje corporal y la expresión facial, las categorías a las que los jueces les dan mayor relevancia porque involucran la capacidad de la participante para aprender a usar su cuerpo y su rostro. La súper modelo que logrará el triunfo debe desarrollar sus talentos para poder destacar entre las demás; y eso se logrará gracias a los consejos y al entrenamiento que les dan los jueces.

Desde un análisis holístico, se puede afirmar que los momentos del juicio estético mencionados por Bosch (2012) se aprecian en ANTM. Estos momentos se pueden relacionar con las categorías que se analizan en el artículo y que permiten que estas mismas se dividan en 3 grupos teniendo en cuenta las características de cada una: lo físico, lo innato y lo aprendido. 
El primer momento hace referencia al primer encuentro con lo potencialmente bello, en esta etapa solo se percibe lo puramente corpóreo de la persona, lo que atrae, lo que a simple vista llama la atención; es por eso, que este momento es la categoría de contextura física a la que hacen referencia los jueces. Como se aprecia, esta categoría es la menos valorada por los jueces. La mera presencia externa y física apela a una visión superficial de la belleza, pero esta concepción es claramente superada en ANTM, porque se trata de la categoría a la que menos se apela en la temporada analizada.

En el segundo momento se advierte y se conoce a la persona, su manera de pensar y de actuar. En este reality show, se logra este momento cuando los jueces tienen el primer contacto con las participantes; es así que las categorías agrupadas son las innatas de cada persona, como son la personalidad y la actitud ante los jueces. Estas categorías, según el análisis de los comentarios, tienen una relevancia media. Se apela a ellas, pero no alcanzan un rol determinante para la selección de la ganadora.

Es en el tercer momento donde se aprecia a las categorías que responden a lo aprendido por las participantes. Estas categorías son a las que los jueces le dan mayor relevancia al juzgar a la concursante. Las categorías de dominio escénico, lenguaje corporal y expresión facial pertenecen a este momento porque es donde se establece una conexión entre lo que la participante muestra y lo que debe reflejar. Asimismo, estas categorías, que expresan una visión que supera cualquier estereotipo físico de belleza, son las que apelan a un sentido profesional del modelaje.

Al pasar por estas tres etapas se llega al último momento en el que se determinará si verdaderamente una persona es bella. Los jueces de America's Next Top Model son quienes usan, de una manera inconsciente, este juicio estético para criticar el trabajo y el esfuerzo de cada una de las participantes del reality show. Son ellos quienes dan a conocer mediante sus valoraciones si es que la concursante ha aprendido y aplicado lo necesario para lograr ser la ganadora del concurso.

\section{Conclusión}

En los apartados anteriores se ha ahondado en un marco teórico que apoye la metodología de investigación utilizada para el análisis de America's Next Top Model. Lo que se buscaba identificar en el análisis es si el contenido de este reality de belleza podría tener un mensaje que aporte formación y crecimiento al espectador que lo consume. Es así, que con el estudio se puede afirmar que el reality show tiene desde la propuesta cognitiva, un punto de partida coherente con una visión integral de la belleza. No refuerza los estereotipos de belleza femenina superficial, sino que apela a rasgos como la actitud y el profesionalismo en las pasarelas. Los argumentos de los jueces le dan mayor importancia a las características aprendidas en el transcurso del concurso por las participantes.

La belleza es el motor del reality show analizado, pero no solo es una belleza física y superficial sino una belleza que tiene las particularidades de haber sido aprendida con ayuda 
de los jueces, y en la que se valora también la personalidad y carácter de la concursante. Al ver algo bello atrae pero no toda la belleza es comprendida a simple vista porque hay lenguajes necesarios para expresarla que no son comprensibles en el primer encuentro (Banús, 2012). Esta es la percepción de la belleza en este reality show.

Además, se debe señalar que no se debe estereotipar a la "telerrealidad" como el espectáculo que toca temas que generan actitudes y representaciones negativas en la sociedad. El reality show analizado, America's Next Top Model, logra enviar un mensaje que supera una visión superficial y banal de la realidad, enfocándose en la belleza interior de la persona y en la profesionalización de la misma. En el programa es indispensable la enseñanza, el conocimiento y las ganas de aprender.

\section{Fuentes consultadas}

Aizen, M. (2000, 25 de agosto). "Récord de audiencia de un concurso de supervivencia por tevé". Extraída el 24/VIII/2015 desde de http://edant.clarin.com/diario/2000/08/25/s-04901. htm

Arboccó, M. y O’Brien, J. (2012). “Impacto de la 'televisión basura' en la mente y la conducta de niños y adolescentes”. Avances en psicología. Vol. 20, núm. 2, pp. 43-57.

Arriaga, M. (ed.) (2008). Sin carne: representaciones y simulacros del cuerpo femenino. Sevilla: Arcibel.

Athié, R. (2012). "Una nueva sensibilidad para captar la belleza”, pp. 575-577. En La comunicación de la belleza a través de la palabra. Su actor y receptor. Actas del VI Encuentro Mesoamericano "Escritura-Cultura", IV Coloquio "Escritoras y Escritores Latinoamericanos”. San José: Promesa.

Banús, E. (2012). "Belleza y percepción de la belleza”, pp. 370-392. En La comunicación de la belleza a través de la palabra. Su actor y receptor. Actas del VI Encuentro Mesoamericano “Escritura-Cultura”, IV Coloquio “Escritoras y Escritores Latinoamericanos”. San José: Promesa.

Barrera, C. (1994). "La crítica de los reality show en la prensa”. Comunicación y Sociedad, num. 7, pp. 89-97.

Bosch, M. (2012). El poder de la belleza. Pamplona: EUNSA.

Cabrera, J. (2012). "La belleza: anotaciones para apuntar a una visión más unitaria de Gabriel Dondo", pp. 78-82. En La comunicación de la belleza a través de la palabra. Su actor y receptor, Actas del VI Encuentro Mesoamericano "Escritura-Cultura", IV Coloquio "Escritoras y Escritores Latinoamericanos”. San José: Promesa. 
Castro, C. (2002). "La hibridación en el formato y pautas para el análisis de Gran Hermano". Zer Revista de estudios de comunicación, núm. 7, pp. 45-59.

Costa, C. (2010) “Coaching-shows: Análisis de un nuevo género televisivo”. Área Abierta, núm. 27, pp. 1-15.

Cotelo, J. (1994). "Defensa del reality show”. Comunicación y Sociedad, núm. 7, pp. 5561.

Ganetz, H. (2011). "Fame Factory: Performing Gender and Sexuality in Talent Reality Television”. Culture Unbound, núm. 3, pp. 401-417.

García, M. (2011). "Estrategias de hibridación en telerrealidad en programas de televisiones generalistas". Quaderns del CAC, núm. 14, pp. 43-48.

Gardner, H. (2011). Verdad, belleza y bondad reformuladas. La enseñanza de las virtudes en el siglo XXI. Barcelona: Paidós.

León, B. (coord.) (2009). Telerrealidad: el mundo tras el cristal. Sevilla: Comunicación Social.

Loscertales, F. y Núñez, T. (2009). “La imagen de las mujeres en la era de la Comunicación”. Revista Científica de Información y Comunicación, núm. 6, pp. 427- 462.

Loverude, R. (2011). “America's Next Top Model is... Enforcing or Resisting Hegemonic Heterosexuality”. Disertación doctoral. Minnesota: Universidad de Minnesota.

Maestre, D. (2005). "Realitys show: El verdadero cerdo mediático". Comunicar: Revista científica iberoamericana de comunicación y educación. Extraída el 24/VIII72015 desde http://www.revistacomunicar.com/verpdf.php?numero=25\&articulo=25-2005-148

Mansur, J. (2012). "Una fenomenología de la conciencia histórica”, pp. 573-574. En La comunicación de la belleza a través de la palabra. Su actor y receptor. Actas del VI Encuentro Mesoamericano "Escritura-Cultura", IV Coloquio "Escritoras y Escritores Latinoamericanos”. San José: Promesa.

Martínez, V. (2007). "El análisis de las audiencias de la 'telebasura' desde la óptica de la teoría de la espiral del silencio”. Hologramática, núm. 2, pp. 39-55.

Mateos-Pérez, J. (2011). "La telerrealidad en las televisoras españolas (1990-1994)". Comunicación y Sociedad, núm. 15, pp. 169-194.

Murolo, L. (2009). "Sobre los estereotipos de la belleza creados por el sistema, impuestos por los medios de comunicación y sostenidos por la sociedad”. Questión, núm. 1, pp. 1-4. 
Oliva, M. (2009). “¡Transfórmate, por favor! Un análisis semio-narrativo de los realities de transformación”, pp. 36-47. En León, B. (coord.). Telerrealidad. El mundo tras el cristal. Sevilla: Comunicación Social.

Perales, F. (2011). "La realidad mediatizada: el reality show". Revista Comunicación, núm. 1, pp. $120-131$.

Rosario-Calender, B. (2012). "La belleza y la vida interior de la conciencia”, pp. 581-583. En La comunicación de la belleza a través de la palabra. Su actor y receptor. Actas del VI Encuentro Mesoamericano "Escritura-Cultura", IV Coloquio "Escritoras y Escritores Latinoamericanos”. San José: Promesa.

Soley-Beltran, P. (2012). "Muñecas que hablan. Ética y estética de los modelos de belleza en publicidad y moda". Revista de Dialectología y Tradiciones Populares, núm. 67, pp. 115-146.

Walzer, A. (2009). "Pedagogías del cuerpo. La construcción espec(tac)ular del cuerpo femenino en el reality show español”. Extraída el 24/VIII/2015 desde http://www. revistalatinacs.org/09/art/18_817_24_U3CM/Alejandra_Walzer.html 